\title{
Ximenia americana: Chemical and Spectral Studies of Extracts of Seeds. Analysis of Trimethylsilyl Derivatives by Gas Chromatography and Mass Spectrometry
}

\author{
Romézio Alves Carvalho da Silva*, Telma Leda Gomes de Lemos, Daniele Alves Ferreira, \\ Francisco José Queiroz Monte \\ Programa de Pós-Graduação em Química, Department of Organic Chemistry e Inorganic, Federal University of \\ Ceará, Fortaleza, Brazil \\ Email: *romezioac@gmail.com
}

Received 2 January 2016; accepted 30 January 2016; published 2 February 2016

Copyright @ 2016 by authors and Scientific Research Publishing Inc.

This work is licensed under the Creative Commons Attribution International License (CC BY). http://creativecommons.org/licenses/by/4.0/

(c) (;) Open Access

\begin{abstract}
Among the numerous botanical species found in the Brazilian plant biome, Ximenia americana is widespread in the Northeast of Brazil, especially in the state of Ceará, where it is known as bush plum. Its bark, leaves and roots are used in popular medicine for the treatment of skin infections, hemorrhoids, stomach ulcers, gastric pain, among others. In this work, hexane and ethanolic extracts of $X$. americana seeds were subjected to silylation reactions followed by analysis of the silylated derivatives by gas chromatography-mass spectrometry (GC/MS). In the hexane extract, 18 substances were identified, where the most abundant and most important components were the Octadec-9-enoic $(38.14 \%),(9 Z, 12 Z)$-Octadec-9,12-dienoic $(18.83 \%)$, Ethanedioic $(8.21 \%)$ and $(Z, Z, Z)-9,12,15-0 c t a d e c a t r i e n o i c(7.22 \%)$ acids. From the ethanol extract 18 substances were also identified having D-Sucrose (29.36\%), L-Sorbose (9.19\%), syllo-Inositol (8.34\%) and D-Glucose (7.45\%) as the main components. In addition, the presence of a steroid in hexane extract and triterpenes in ethanol extract was recorded. The constituents were identified using chromatographic and spectrometric methods, especially gas chromatography-mass spectrometry. To our knowledge, this is the first study of this nature from the oil of the $X$. american seeds.
\end{abstract}

\section{Keywords}

Ximenia americana, Seeds, TMS Carbohydrates Derivatives, GC/MS

\footnotetext{
${ }^{*}$ Corresponding author.
} 


\section{Introduction}

Brazil is considered the country with the greatest biological diversity. It houses about 14\% of the world's plant diversity distributed in different biomes, mainly the Amazon region, the Atlantic Forest and Caatinga [1]. The “caatinga” is an exclusively Brazilian biome. It reaches an area of 850 square kilometers, occupying about $10 \%$ of Brazilian territory and is present mainly in the interior of Northeast Brazil and northern Minas Gerais state [2]. Basically is formed by xerófilas plants or adapted to dry conditions (found in semiarid northeast). It has been recorded about a thousand plant species in the "caatinga". According to experts, there may be double that amount. Importantly, the investigation in natural products assumed a great sense of urgency in response to the expanding human population and its consequent demand for food and good health. However, while many countries increase their investments in chemistry and pharmacology of natural products derived from plants, investments in Brazil are still quite insufficient in this area. The Ximenia genus (Olacaceae) comprises about 8 species [3], Ximenia americana being the most common. It is popularly known as “ameixa do mato”, “ameixa de espinho" and "ameixa da Bahia” and is widely distributed in northeast Brazil. A tea obtained from its barks has been used in popular medicine as cicatizing, adstringent and as an agent against excessive menstruation. As a powder, it treats stomach ulcers and the seeds are purgative [4] [5]. In previous phytochemical study [6], the stem and roots of this plant were found to contain saponins, glicosydes, flavonoids, tannins, phenolics, alkaloids, quinones and terpenoids types. In addition, the plant is potentially rich in fatty acids and glycerides and the seeds contain derivatives cyanide. Concerning the fatty acids, in addition to common $\mathrm{C}_{16}, \mathrm{C}_{18}$ and $\mathrm{C}_{22}$, a distinctive feature is the presence of acetylenic fatty acids. Our continuing interest in the chemistry of $X$. americana led us to investigate its seeds, still little studied from the chemical and pharmacological aspects. The hexanic and ethanolic extracts of $X$. americana were found to contain besides triglycerides, various fatty acids, furanoses/ pyranoses carbohydrates, steroids and triterpenoids. The identification of components was made through chemical and spectral studies.

\section{Experimental Part}

\subsection{General}

GC/MS analysis were performed on Shimadzu GCMS model QP2010SE Plus using a (5\%-phenyl)-dimethylpolysiloxane Rtx ${ }^{\circledR}-5 \mathrm{MS}$ capillary column $(30 \mathrm{~m} \times 0.25 \mathrm{~mm} \times 0.25 \mu \mathrm{m})$ with film thickness $0.1 \mu \mathrm{m}$; the temperatures of the injector and detector were $260^{\circ} \mathrm{C}$ and $300^{\circ} \mathrm{C}$, respectively; column conditions: $60^{\circ} \mathrm{C}(0.5 \mathrm{~min})$ to $260^{\circ} \mathrm{C}(5 \mathrm{~min})$ at $6^{\circ} \mathrm{C} / \mathrm{min}$, then $12^{\circ} \mathrm{C} / \mathrm{min}$ to $300^{\circ} \mathrm{C}(10 \mathrm{~min})$ using He as carrier gas, flow rate $1.7 \mathrm{~mL} / \mathrm{min}$ with split mode. The analysis with the mass detector was performed in the scan mode with analysis time of 52.21 minutes; EIMS data were recorded with electron impact ionization at $70 \mathrm{eV}$ (1.5 KV voltage, analyzer quadrupole and ion source $200^{\circ} \mathrm{C}$ ), in the range $47-600 \mathrm{Da} .{ }^{1} \mathrm{H}$ - and ${ }^{13} \mathrm{C}$-NMR spectra were recorded on Brucker DRX 500 spectrometer in $\mathrm{C}_{5} \mathrm{D}_{5} \mathrm{~N}$ and are reported in ppm relative to using tetramethylsilane (TMS) as internal standard; IR spectra were recorded on Perkin-Elmer model Spectrum 100 FT-IR using a Universal Attenuated Total Reflectance (UATR). All solvents and reagents were of analytical grade and obtained from commercial sources (Synth and Merck). Silica gel 70 - 230 mesh (Merck) was used for column chromatography; silica gel Merck Kieselgel 60 (2 - 25 mm silica gel) with fluorescent indicator on aluminum support paper (Merck F254) was used for thin-layer chromatography (TLC) and UV light (254 and $365 \mathrm{~nm}$ ) and vanillin/ perchloric acid/EtOH solution under heating, as developing agents. Mp’s were determined on digital Mettler Toledo, model FP62 apparatus and are uncorrected.

\subsection{Plant Material}

Seeds of $X$. americana were collected in Marrecas site, near the city of Acarape, Ceará, Brazil in 2014. A voucher specimen ( $\mathrm{N}^{\circ}$ 040411) is deposited at the Herbarium Prisco Bezerra of the Department of Biology, Federal University of Ceará, Fortaleza, Brazil.

\subsection{Isolation of Triterpenoids}

On concentration in vacuo, the crude EtOH extract afforded a greenish-white precipitate, which was filtered. The precipitate after successive washes with $\mathrm{MeOH}$ resulted in a white solid (60 mg) amorphous soluble in pyridine, which was characterized as a triterpenes mixture: $\mathrm{mp} 209^{\circ} \mathrm{C}-212^{\circ} \mathrm{C}$. 


\subsection{Isolation of Triglycerides}

The hexane fraction $(2.1 \mathrm{~g}$ ) of hexane extract was subjected to column chromatography on silica gel, eluted with increasing concentrations of EtOAc in hexane. After thin layer chromatography, the fractions 17 - 20 eluted with hexane-EtOAc 4:3, was rechromatographed on silica gel column eluted with increasing concentrations of $\mathrm{CH}_{2} \mathrm{Cl}_{2}$ in hexane. Thin layer chromatography brought together all fractions 16 - 44 (eluted with hexane-dichloromethane 1:1), which were then characterized as triglycerides.

\subsection{Synthesis of Trimethylsilyl Derivatives}

The extracts were submitted to a silylation reaction according to a known methodology [7] with slight modifications. Hexane extract $(2 \mathrm{mg})$ was treated with BSTFA $(100 \mu \mathrm{L})$ and TMCS $(1 \%)$ and the mixture was stirred for $1 \mathrm{~h}$ at $60^{\circ} \mathrm{C}$, followed by analysis by GC/MS.

\section{Results and Discussion}

In separate experiments, hexane and ethanol crude extracts of $X$. anericana seeds were successively partitioned into hexane, dichloromethane, ethyl acetate and methanol. Considering one of the main objectives of this study, namely the identification of oil components of the seed $X$. americana, using mainly gas chromatography coupled to mass spectrometry (GC/MS) and, without knowing the types of compounds present (hydrocarbons, alcohols, organic acids, esters of fatty acids, steroids, sugars, among others), preparation of volatile derivatives has become a basic requirement. Thus, the crude hexane was subjected to silylation reaction with BSTFA/ TMCS followed by obtaining a chromatogram (GC) of the crude reaction product. The structures of the components corresponding to 18 peaks in the chromatogram of total ion were identified by GC/MS from the fragmentation pattern observed in their mass spectra, and by the comparison to the mass spectra reported in the literature.

Among the identified compounds (Table 1 ), most are fatty acids, especially the hexadecanoic (palmitic acid), (Z,Z,Z)-9,12,15-octadecatrienoic ( $\alpha$-linolenic acid), (9Z,12Z)-octadec-9,12-dienoic (linoleic acid) and octadec-9enoic (oleic acid ) acids, the latter as the major component. It is also worth reporting the presence of the steroid $\beta$-Sitosterol (3.4\%).

The MS of the TMS derivatives of these acids exhibit a characteristic profile fragmentation. Thus, their MS in addition to peaks due to $[\mathrm{M}]^{+}$show peaks at $\mathrm{m} / \mathrm{z} 73,117,132,145$ and 313 corresponding to fragments $\left.\left.\left.\left.\left[\mathrm{CH}_{3}\right)_{3} \mathrm{Si}\right]^{+},\left[\mathrm{CH}_{3}\right)_{3} \mathrm{SiCO}_{2}\right]^{+},\left[\mathrm{CH}_{3}\right)_{3} \mathrm{SiCO}_{2} \mathrm{CH}_{3}\right]^{+},\left[\mathrm{CH}_{3}\right)_{3} \mathrm{SiCO}_{2} \mathrm{C}_{2} \mathrm{H}_{4}\right]^{+}$and $\left.\left[\mathrm{CH}_{3}\right)_{2} \mathrm{SiCO}_{2} \mathrm{C}_{15} \mathrm{H}_{31}\right]^{+}$, respectively. In general, at $70 \mathrm{eV}$ eims of these trimethylsilyl derivatives, $\mathrm{m} / \mathrm{z} 73[\mathrm{TMS}]^{+}$is registered as the base peak. Taken as an example, the mass spectrum (Figure 1) of the component with retention time 24.0 (Table 1) which was identified as the palmitic acid $\left(\mathrm{RCO}_{2} \mathrm{TMS}, \mathrm{R}=\mathrm{C}_{15} \mathrm{H}_{31}\right)$ showed a molecular peak at $\mathrm{m} / \mathrm{z} 328$.

The loss of methyl radical to give the ion at $m / z 313$ (M-15), occurs mainly from the silyl group [8] because at this point, the cation is more stable (Scheme 1). The ions at $m / z 145$ and 132 were explained by the fission of the bond $\beta, \gamma$ (relative to the carbonyl group) of the chain $\mathrm{R}$ with possible transfer of hydrogen via a mechanism involving four centers, and through the expected McLafferty rearrangement [9] [10], respectively.

Also, the mass spectra of silylated fatty acids containing a double bond showed virtually the same behavior. Even those containing more than one double bond, but showing differences, exhibited a similar profile. However, the peaks corresponding to the fragments at $\mathrm{m} / \mathrm{z}$ 117, 132 and 145 in these latter cases were much less intense.

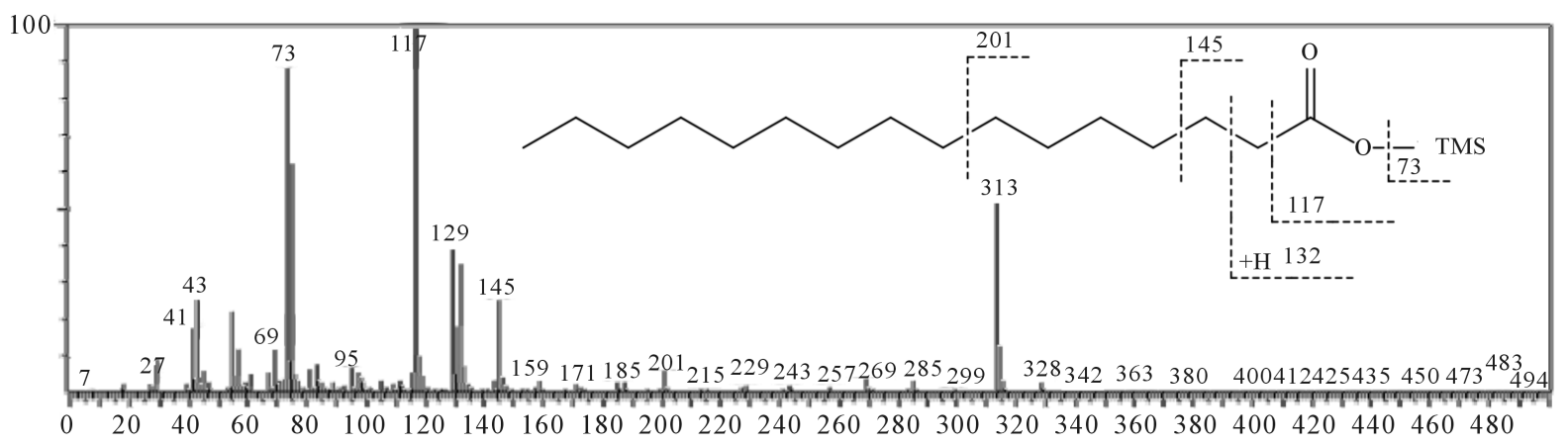

Figure 1. Mass spectrum of the TMS-hexadecanoic acid (palmitic acid). 


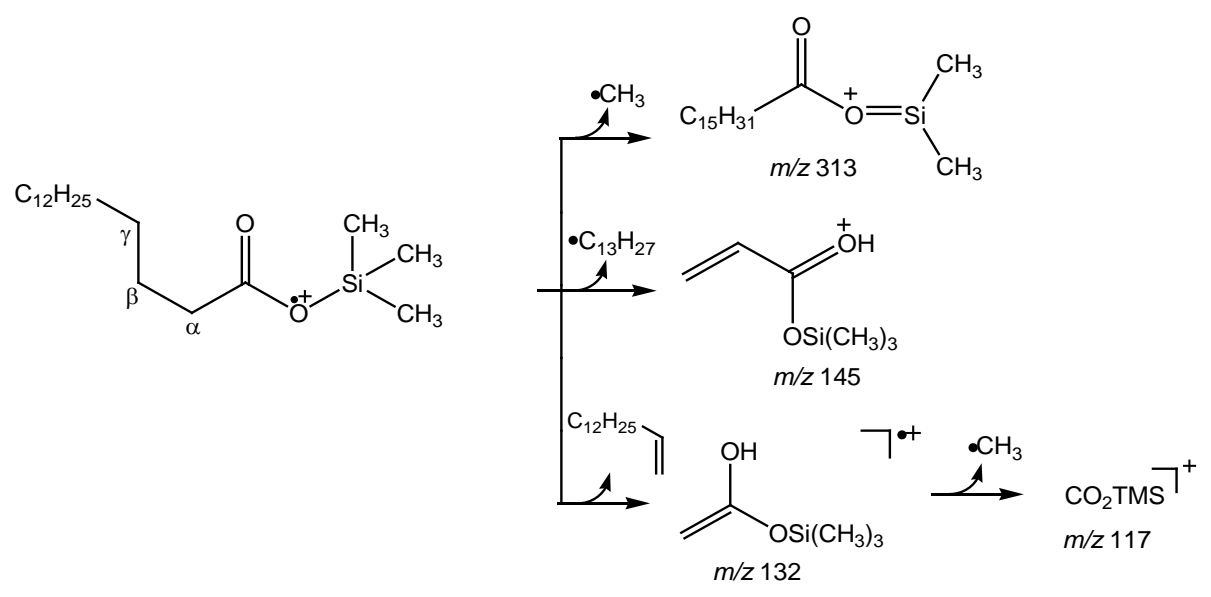

Scheme 1. Mass spectral fragmentation observed for TMS-hexadecanoic acid (palmitic acid).

Table 1. Components of the hexane extract of the seeds of $X$. americana.

\begin{tabular}{|c|c|c|c|c|}
\hline Peak & Compounds & RT & $\%$ & Mass spectra, $m / z$ (rel. intensity) \\
\hline 1 & Ethanedioic acid & 6186 & 8.21 & 73(29), 75(39), 90(28), 147(100) \\
\hline 2 & Disiloxane, hexamethyl- & 7100 & 5.10 & 66(12), 73(22), 147(100), 148(17) \\
\hline 3 & Pentasiloxane, dodecamethyl- & 8732 & 0.69 & 73(81), 147(100), 281(91), 369(18) \\
\hline 4 & Glycerol & 10,957 & 0.76 & 73(100), 103(18), 117(19), 147(49), 205(22), 218(14) \\
\hline 5 & n.i. & 12,230 & 1.89 & 73(66), 146(100), 205(62), 279(51), 367(100) \\
\hline 6 & Nonadioic acid & 20,403 & 0.97 & 55(46), 73(100), 75(76), 117(28), 129(30), 317(21) \\
\hline 7 & Hexadecanoic acid & 24,023 & 4.17 & $\begin{array}{c}\text { 73(89), 75(62), 117(100), 129(40), 132(35), 145(26), } \\
\text { 313(52), 328(5) }\end{array}$ \\
\hline 8 & 9,12-Octadecadienoic acid $(Z, Z)-$ & 26,297 & 18.83 & 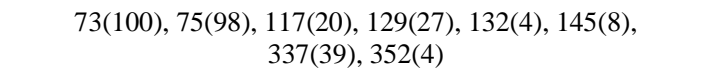 \\
\hline 9 & cis-9-Octadecenoic acid & 26,358 & 38.14 & $\begin{array}{c}\text { 73(100), 75(85), 117(65), 129(70), 132(19), 145(33), } \\
\text { 339(47), 354(6) }\end{array}$ \\
\hline 10 & trans-9-Octadecenoic acid & 26,440 & 1.70 & $\begin{array}{c}\text { 73(100), 75(80), 117(80), 129(49), 132(15), 145(40), } \\
\text { 339(67), 354(7) }\end{array}$ \\
\hline 11 & Octadecanoic acid & 26,666 & 2.17 & $\begin{array}{c}\text { 73(79), 75(58), 117(100), 129(38), 132(37), 145(27), } \\
341(50), 356(4)\end{array}$ \\
\hline 12 & Linolenic acid & 27,887 & 7.22 & $\begin{array}{c}\text { 73(80), 75(83), 79(100), 117(22), 129(19), 132(4), } \\
\text { 145(10), 335(7), 350(3) }\end{array}$ \\
\hline 13 & 9,12-Octadecadiynoic acid & 28,907 & 2.52 & $\begin{array}{c}\text { 73(95), 75(100), 91(82), 105(84), 117(50), 119(58), 129(29), } \\
\text { 132(7), 145(12), 148(57), 333(8), 348(4) }\end{array}$ \\
\hline 14 & $\begin{array}{l}\text { trans-Octadec-11-en-9-ynoic acid, } \\
\text { 8-trimethylsilyloxy-, methyl ester }\end{array}$ & 29,526 & 1.24 & 73(100), 147(13), 217(12), 237(90), 365(4) \\
\hline 15 & 1-Monooleoylglycerol & 32,741 & 0.90 & $\begin{array}{l}\text { 55(55), 73(94), 103(48), 117(18), 129(100), 147(71), 201(20), } \\
\text { 203(28), 205(12), 265(9), 397(40), 410(5), 485(6), 500(3) }\end{array}$ \\
\hline 16 & Tetracosanoic acid & 33,449 & 0.58 & $\begin{array}{c}\text { 73(100), 75(75), 117(79), 129(30), 132(34), 145(33), 201(12), } \\
425(40), 440(8)\end{array}$ \\
\hline 17 & cis-15-Tetracosenoic acid & 37,198 & 1.13 & $\begin{array}{c}\text { 73(100), 75(82), 117(62), 129(68), 132(22), 145(34), } \\
423(32), 438(8)\end{array}$ \\
\hline 18 & $\beta$-Sitosterol & 39,343 & 3.04 & $\begin{array}{c}\text { 43(58), 73(52), 129(100), 255(14), 357(42), 381(22), } \\
\text { 396(40), 471(9), 486(14) }\end{array}$ \\
\hline 19 & Lupeol & 43,736 & 0.74 & $\begin{array}{c}\text { 73(50), 189(100), 203(52), 218(38), 279(10), 369(12), } \\
\text { 393(9), 408(5), 483(4), 498(9) }\end{array}$ \\
\hline
\end{tabular}

n.i.: no identified. 
Steroids in general, exhibit a very similar fragmentation pattern. The mass spectrum of the constituent with retention time 39.343 in the chromatogram showed a molecular peak at $m / z 486$ and was identified as $\beta$-Sitosterol. The peaks at $\mathrm{m} / \mathrm{z}$ 471, 396, 381, 357, 213 and 129, are the most representative, since they correspond to fragments of higher mass and are relatively more prominent peaks. The ion at $m / z 471$ (M-15) can occur in two paths (Scheme 2): fission of the C-Si bond (a) or the $\mathrm{C}_{10}-\mathrm{C}_{19}$ bond (b). Studies [11] from similar compounds demonstrated that the most attractive site of methyl cleavage is at the C-Si bond (a), a type of fragmentation very common in the mass spectral fragmentation of TMS ethers and esters. The ion at $m / z 396$ (M-90) was justified due to the loss of trimethylsilanol (TMS-OH) with the formation of ionized diene (c). Studies with 2,2,4,4- $d_{4}$ steroids suggests that some of the migrant hydrogen comes from C-4 and on the basis of stereochemical considerations it seems most likely the $4 \beta$ hydrogen is probably migrant [11] (Scheme 2). In addition,

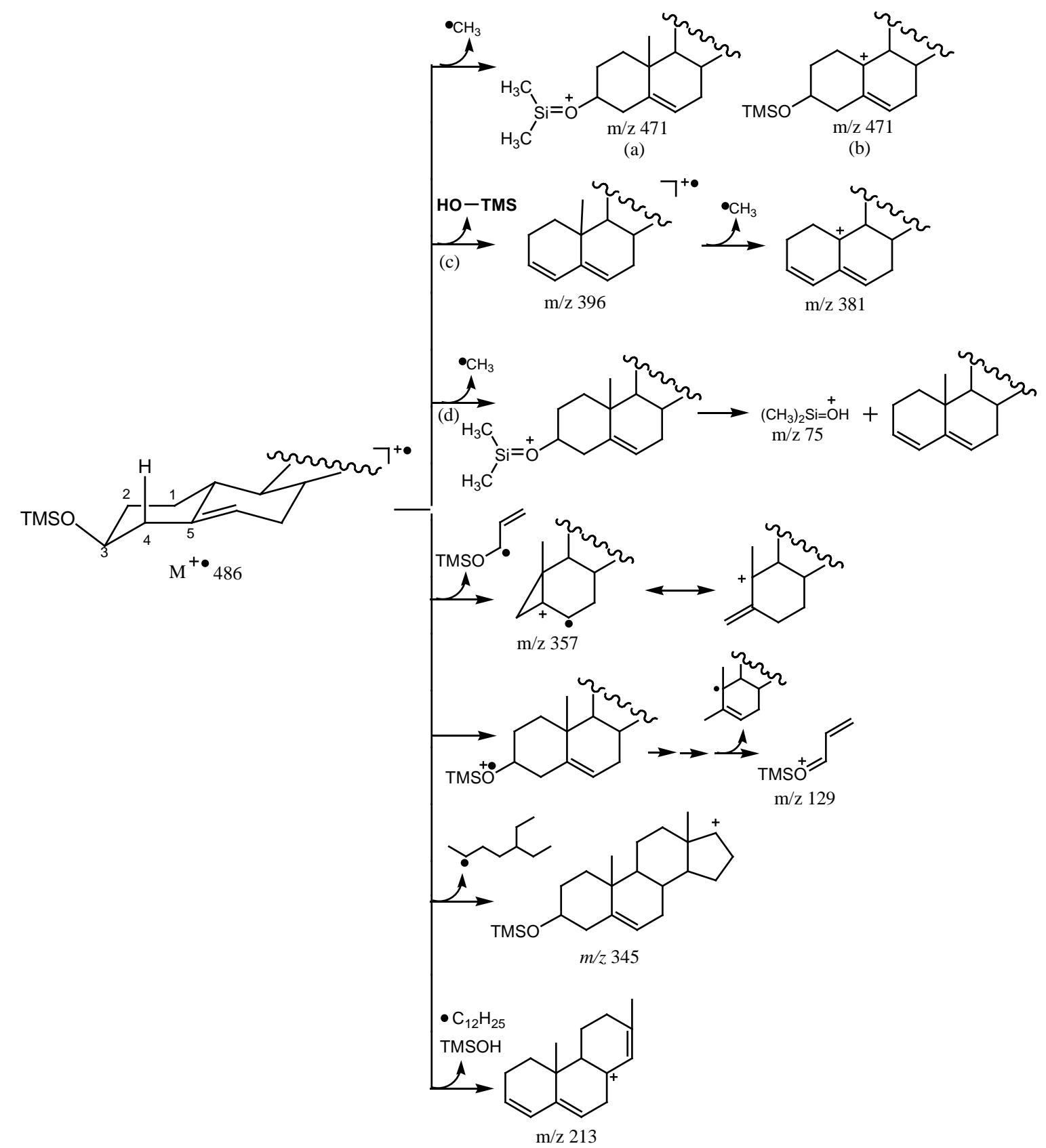

Scheme 2. Mass spectral fragmentation observed for TMS- $\beta$-Sitosterol. 
another fragmentation (d) related to the M-90 results in one fragment at $\mathrm{m} / \mathrm{z} 75$, for which high-resolution mass measurements [11] indicated the composition $\left(\mathrm{CH}_{3}\right)_{2} \mathrm{SiOH}$. This fragment results from cleavage of a methyl radical from the TMS function followed by loss of the dimethylsilanol moiety. Deuterium labeling and methyl substitution at C-4 reveal a situation identical with the hydrogen transfer involved in the M-90 fragmentation, namely, that only some (40\%) of the hydrogen originates from the C-4 position and that it is probably the axial $4 \beta$ hydrogen atom that is implicated [11]. In turn, the fragment at $\mathrm{m} / \mathrm{z} 396$ loses methyl radical to yield the $\mathrm{m} / \mathrm{z}$ 381. According to the literature [10], in the formation of $\mathrm{m} / \mathrm{z} 357$, the hydrogen atom H-2 it is transferred to C-6 carbon through six-atom system, followed by cleavage of the allylic bond C-3-C-4 and rearrangement of the ring A. Other typical ions $(\mathrm{m} / \mathrm{z} 303,275,213,184,121,95,57,43)$, resulting from the cleavage of the steroidal skeleton and of the side chain were observed [9] [11] [12]. The base peak at $m / z 129$ was justified by a complex fragmentation occurred in ring A. Labeling studies [11]-[13] with deuterium showed that the $\mathrm{C}_{4}$ carbon is not part of ion $\mathrm{m} / \mathrm{z} 129$ (Scheme 2).

The crude EtOH extract was subjected to reaction silylation with BSTFA/TMCS followed by obtaining a chromatogram GC/MS of the crude reaction product. The structures of the components corresponding to 18 peaks in the chromatogram of total ion were identified by GC/MS from the fragmentation pattern observed in their mass spectra, and by the comparison to the mass spectra reported in the literature. Among the identified substances (Table 2), most are represented by furanosides and pyranosides carbohydrates and the main constituents were D-(+)-Sucrose (29.36\%), L(-)-Sorbose (9.19\%), scyllo-Inositol (8.34\%) and D-Glucose (7.45\%).

\section{Table 2. Components of the EtOH extract of the seeds of X. americana.}

\begin{tabular}{|c|c|c|c|c|}
\hline Peak & Compounds & RT & $\%$ & Mass spectra, $\mathbf{m} / \mathbf{z}$ (rel. intesity \\
\hline 1 & 1,2-Bis(trimethylsiloxy)ethane & 6181 & 2.13 & 147(100), 73(58), 191(23) \\
\hline 2 & Disiloxane, hexamethyl- & 7097 & 1.46 & 66(12), 73(22), 147(100), 148(14) \\
\hline 3 & Glycerol & 10,958 & 5.58 & 73(100), 103(18), 117(19), 147(80), 205(38), 218(15) \\
\hline 4 & n.i. & 14,239 & 1.41 & 172(100), 82(94), 73(22) \\
\hline 5 & beta.-D-Galactofuranoside & 20,404 & 3.04 & 73(100), 217(82), 147(33) \\
\hline 6 & D-Fructose & 20,856 & 1.48 & 73(100), 217(55), 147(25) \\
\hline 7 & Mannonic acid, lactone & 20,982 & 3.08 & 73(100), 217(65), 147(27) \\
\hline 8 & Sorbopyranose, L- & 21,091 & 9.19 & 73(100), 204(68), 217(33) \\
\hline 9 & D-Galactose & 21,182 & 1.54 & 73(82), 204(100), 217(28), 147(51) \\
\hline 10 & Inositol, scyllo- & 21,305 & 8.34 & 305(20), 318 (32), 217(40), 147(42), 191(22), 204(12) \\
\hline 11 & alpha.-D-Glucopyranose & 22,212 & 5.15 & 204(100), 73(82), 191(40) \\
\hline 12 & D-Mannitol & 22,916 & 6.27 & 73(100), 147(51), 319(42) \\
\hline 13 & D-Glucose & 23,521 & 7.45 & 204(100), 191(41), 217(18) \\
\hline 14 & Inositol, myo- & 25,082 & 1.62 & 305(56), 318(30), 217(62), 147(51), 191(30), 204(25) \\
\hline 15 & 9,12-Octadecadienoic acid (Z,Z)- & 26,297 & 1.91 & 73(94), 75(100), 129(25), 337(34) \\
\hline 16 & trans-9-Octadecenoic acid & 26,353 & 3.31 & 73(96), 75(100), 117(79), 129(68), 145(32), 339(42) \\
\hline 17 & $\mathrm{D}(+)$-Sucrose & 31,944 & 29.36 & $\begin{array}{c}\text { 361(100), 73(80), 217(32), 147(23),103(20), } \\
437(12), 540\end{array}$ \\
\hline 18 & $\begin{array}{l}\text { 14,17-Nor-3,21-dioxo-.beta.-amyrin, } \\
\text { 17,18-didehydro-3-dehydroxy- }\end{array}$ & 43,022 & 1.79 & 73(100), 75(90), 117(55) \\
\hline 19 & $\begin{array}{l}\text { Silane, (9,19-cyclo-9.beta.-lanost-24-en-3. } \\
\text { beta.-yloxy)trimethyl- }\end{array}$ & 43,309 & 5.89 & 73(100), 117(62), 75(57) \\
\hline
\end{tabular}

n.i.: no identified. 
The identification of these substances as trimethylsilyl derivatives by GC/MS can be made in view of some mechanistic proposals for characteristic fragments, according to published studies [14]-[16]. For example, the fragments $\mathrm{m} / \mathrm{z} 204$ and 217 are relatively common from mass spectra of trimethylsilyl derivatives of carbohydrates. Both peaks can be seen in mass spectra from TMS ethers, however, the peak at $m / z 204$ is generally the dominant from TMS ethers with pyranose ring, as observed in the spectrum (Figure 2) of the component with retention time 21.091 (Table 2). Its origin can occur by different mechanisms. One them, from the open-chain carbohydrate involves the TMS group via McLafferty type rearrangement [17] [18] the fragment being formed by the C-1-C-2 carbon (Scheme 3).

This two-carbon fragment, $\mathrm{m} / \mathrm{z}$ 204, a common dominant peak of pyranose derivatives (aldo-, keto-, and glycosides), originates the most part, from C-2-C-3 and C-3-C-4 (aldopyranoses) [19] or must contain carbons C-3-C-4 and C-4-C-5 (ketopyranoses) [20] which may be formed from the molecular ion or from $\mathrm{m} / \mathrm{z}$ 437, both by cyclic fragmentation [20] (Scheme 4). In turn, the ion at $m / z$ 437, typical of ketoses [21], results from the loss of C-1 and its substituent by fisson of the C-1-C-2 bond [19] [20].

Thus, by comparing with published data [14] [15], the mass spectrum of the component with RT 20.856 (Table 2) allow the assignment of a pyranose structure to the TMS ether derivative, which was identified as L-Sorbose in pyranose form. On the other hand, the relative intensity of the peak at $m / z 204$, which is most intense peak in the mass spectra of glucopyranosides (Figure 2) is drastically reduced in the mass spectra of glycofuranosides (Figure 3).

The peak at $m / z 217$ (Scheme 5) is characteristic of monosaccharides with furanose ring, which it is usually a very intense peak and, sometimes, the base peak. The relatively high intensity of this peak was observed in the mass spectrum of the component with retention time 20.856 (Table 2). Importantly, the fragment at $\mathrm{m} / \mathrm{z} 217$, according to the literature, is formed by carbon atoms C-2, C-3 and C-4 from aldopyranoses [19] [21] or from other carbons from ketofuranoses [18], but without a specific proposal for fragmentation. On the other hand, its formation generally can occur from other parts of the molecule via rearrangement [19]. One possible mechanism

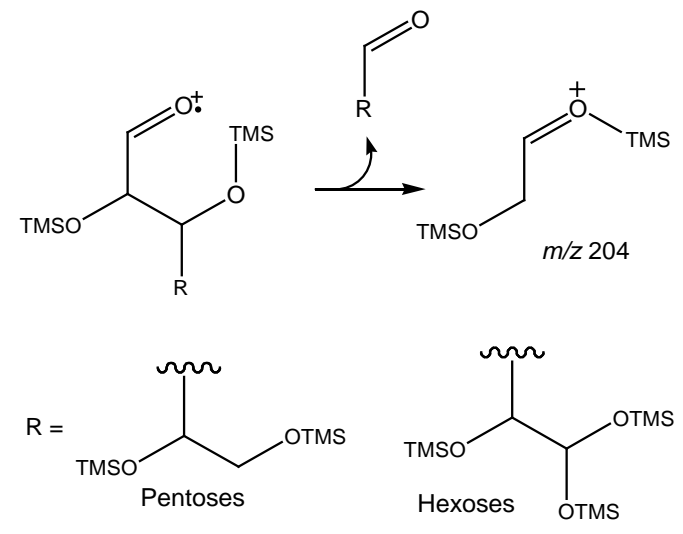

Scheme 3. Formation of fragment $\mathrm{m} / \mathrm{z} 204$ via McLafferty type rearrangement.

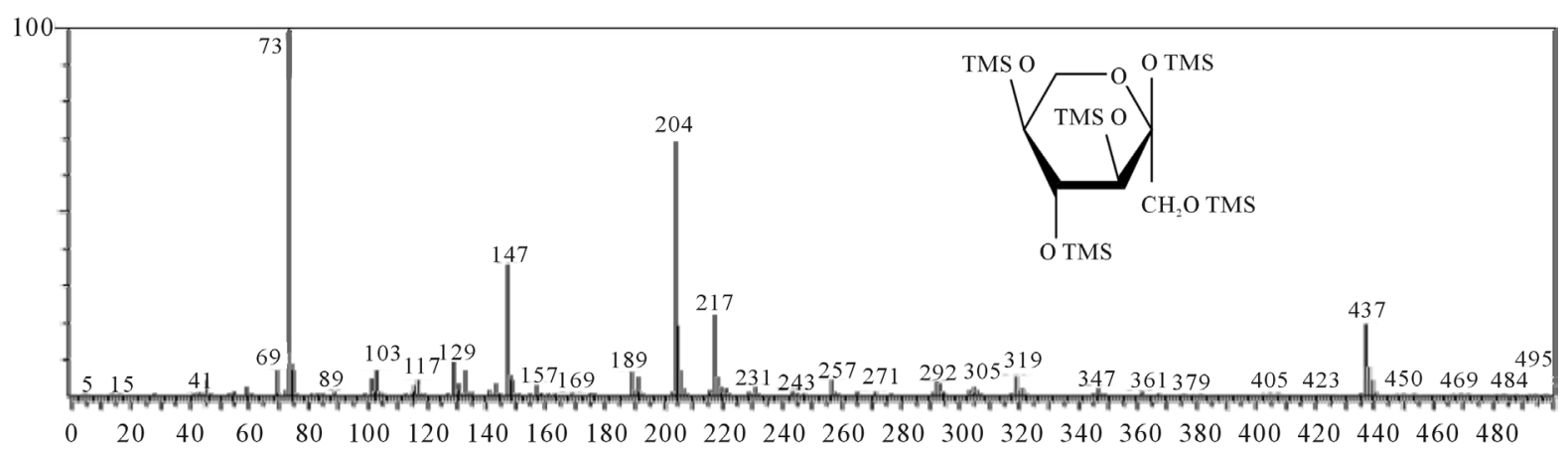

Figure 2. Mass spectrum of TMS-L-Sorbose. 


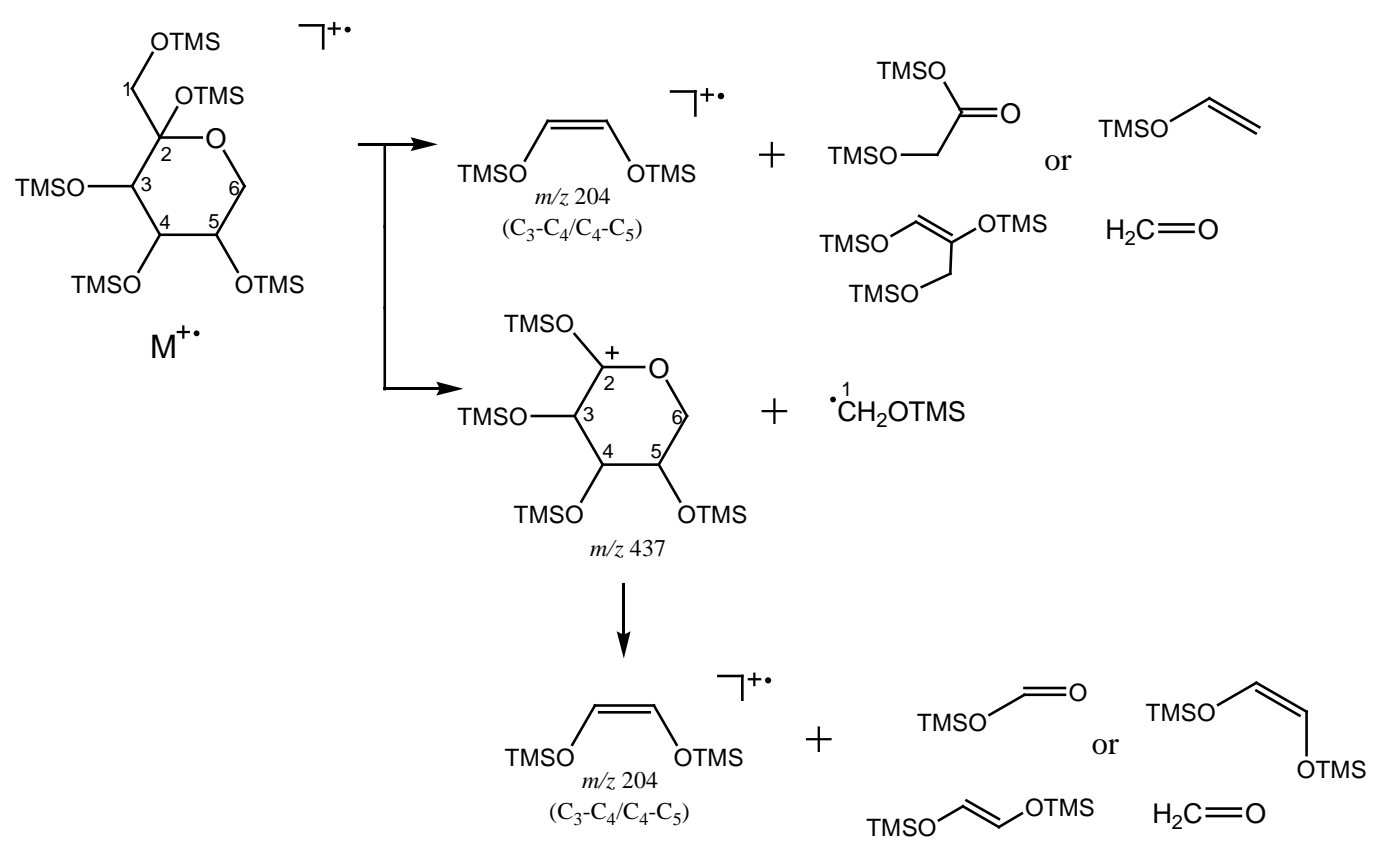

Scheme 4. Formation of fragment at $\mathrm{m} / \mathrm{z} 204$ via the alternative paths.

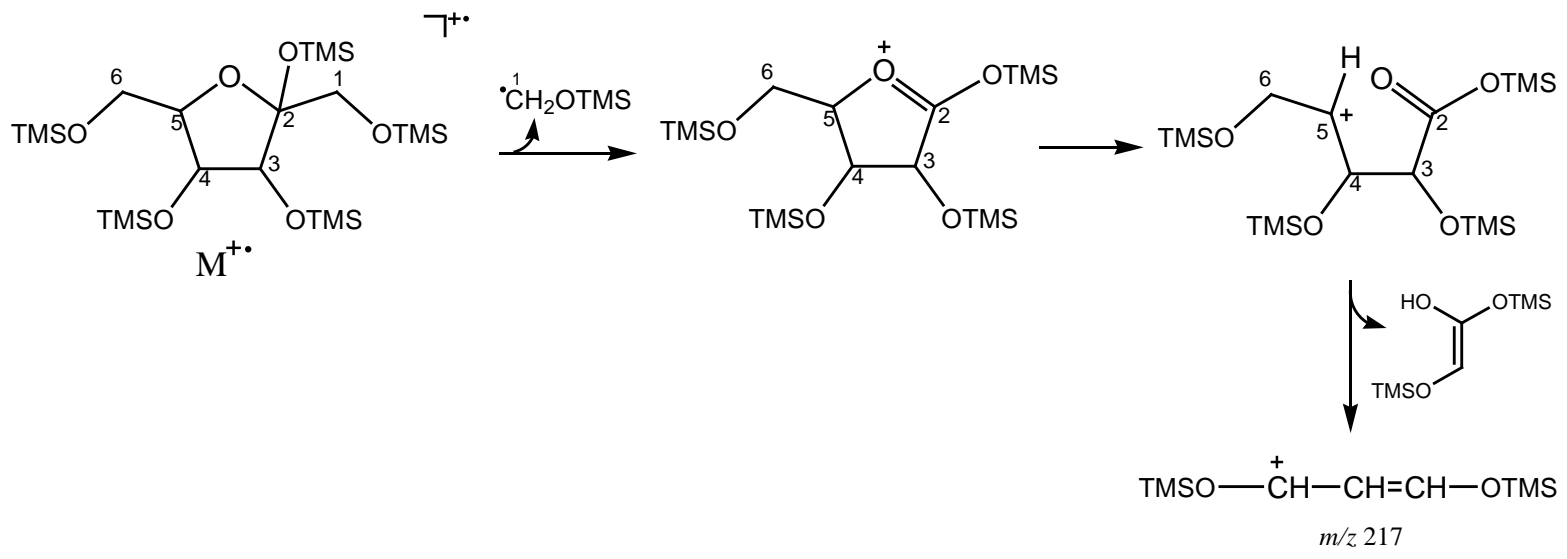

Scheme 5. Formation of fragment $\mathrm{m} / \mathrm{z} 217$ in furanose monosaccharides.

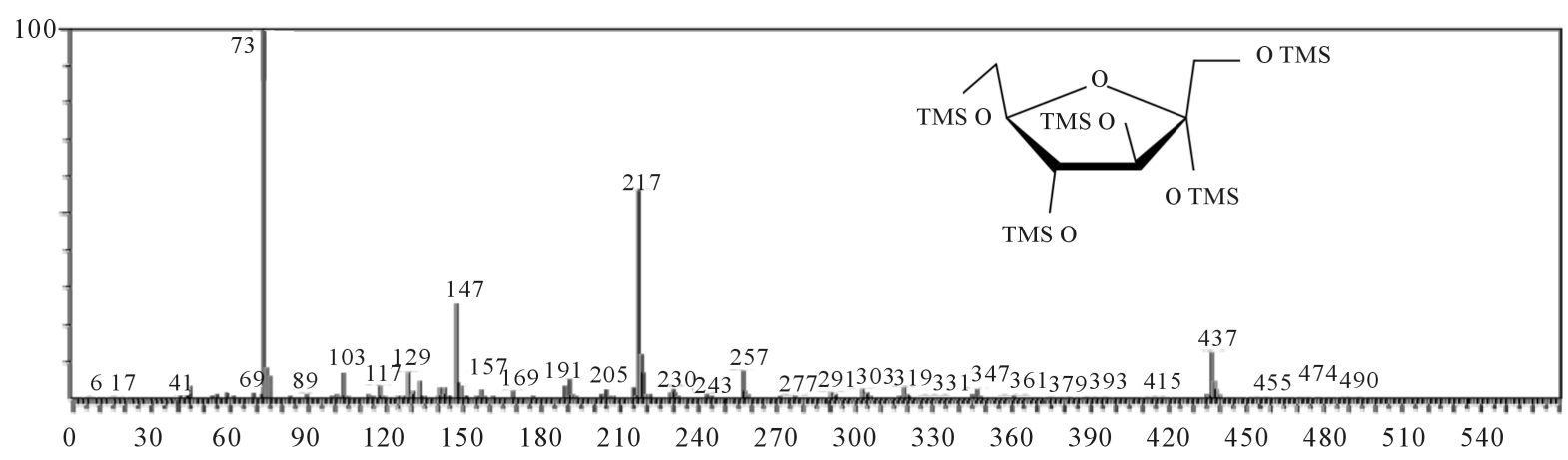

Figure 3. Mass spectrum of TMS-D-Frutose.

involving rearrangement is seen in Scheme 5. In the spectrum (Figure 3) was not observed the molecular ion peak ([M] $]^{+}$540), but was recorded peak at m/z 437 (M-CH 
Thus, by comparing the mass spectra obtained in this study with published data [14] [15], the component (RT 20.856) was identified as the TMS ether of D-Fructose in furanose form.

Finally, by comparing the mass spectrum (Figure 4) component at RT 31.944 with the mass spectra of the literature [16], allowed to identify this component as the disaccharide Sucrose. It is noteworthy peaks at $\mathrm{m} / \mathrm{z} 437$ (M-CH${ }_{2} \mathrm{OTMS}$ ), 361, 319, 217 and 204 (very low intensity) consistent with the pyranose and furanose structures. The other compounds of Table 2 were identified by comparison of retention times and mass spectral data reported in the literature.

An intense peak at $\mathrm{m} / \mathrm{z} 306$ which is generally observed in the mass spectra of carbohydrates in their open forms [21] [22] is not registered in the mass spectra analyzed in the present study. This observation is in agreement with the carbohydrates identified in their cyclic forms.

At the concentration of the ethanolic extract of the seeds gave a precipitate which was recrystallized from $\mathrm{MeOH}$. The ${ }^{1} \mathrm{H}$ NMR spectrum of this recrystallized $(60 \mathrm{mg})$ showed that it was still mixture of two or three closely related compounds: IR spectrum $\gamma$ max $3230(\mathrm{OH}), 2918 / 2910\left(\mathrm{C}_{\mathrm{sp} 3}-\mathrm{H}\right), 1683(\mathrm{C}=\mathrm{O}), 1029(\mathrm{C}-\mathrm{O}) \mathrm{cm}^{-1}$. The ${ }^{1} \mathrm{H}$ NMR spectrum revealed the presence of various methyl groups, one of which (one singlet at $1.80 \mathrm{ppm}$ ) bonded to $\mathrm{sp}^{2}$ carbon; the spectrum also showed signs as broad triplet at $5.72(1 \mathrm{H})$, broad singlet and $5.51(1 \mathrm{H})$ and two broad singlet at $4.96(1 \mathrm{H})$ and $4.78(1 \mathrm{H})$ due to hydrogens mutually coupled. The first two were attributed to olefinic hydrogens and consistent with the presence of triterpenes of oleanane/ursano types [23], while the last two were correlated to vinyl hydrogens in terminal double bond, characteristic of triterpene lupane type [24]. In turn, the ${ }^{13} \mathrm{C}$ NMR spectrum in accordance with the ${ }^{1} \mathrm{H}$ NMR spectrum recorded signals to lupane $\left[\delta_{\mathrm{C}}\right.$ $151.68(\mathrm{C}-20)$ and $110.32(\mathrm{C}-29)]$, as well as signs consistent with oleanane triterpenes $\left[\delta_{\mathrm{C}} 122.92(\mathrm{C}-12), 56.10\right.$ (C-5), 42.36 (C-18), 46.83 (C-19), 33.54 (C-21) and 32.20 (C-22)] [23]-[25]; the spectrum also showed signs at $\delta_{\mathrm{C}} 78,44$ (due to oxygenated $\mathrm{sp}^{3}$ carbon C-3) and 19,12 correlated to methyl carbon C-30 in lupane triterpenoids [24]. In addition, the signals $\delta_{\mathrm{C}} 180.56$ and 179.23 characteristic of carbons of carboxylic acids with relative intensities of 1:2, respectively. The DEPT experiment confirmed the presence of hydrogenated carbon, especially oxygenated $\mathrm{CH}\left(\delta_{\mathrm{C}} 78.44\right), \mathrm{CH}_{2} \mathrm{sp}^{2}\left(\delta_{\mathrm{C}} 110.32\right), \mathrm{CH} \mathrm{sp}^{2}\left(\delta_{\mathrm{C}} 122.92\right), \mathrm{CH} \mathrm{sp}{ }^{3}\left(\delta_{\mathrm{C}} 56.10\right.$ and 42.36$)$ and $\mathrm{CH}_{2} \mathrm{sp}^{3}$ (46.83, 33.54 and 32.20). Based on the spectral comparison with the literature data (also considering the excessive number of signals in the ${ }^{13} \mathrm{C}$ NMR spectrum in the region between 14.00 and $56.00 \mathrm{ppm}$ ), it was concluded that the mixture was formed by triterpenes betulinic acid (56\%), oleanolic acid (35\%), and further a third component, also triterpenic nature in minor proportion $(9 \%)$. The percentages were calculated from the integrations of signals at $\delta_{\mathrm{H}} 3.56,3.47$ and 3.31 in the ${ }^{1} \mathrm{H}$ NMR spectrum, which were correlated with carbinolic hydrogens of the components of the mixture.

\section{Conclusion}

Carbohydrate analysis has proven to be a powerful technique in the understanding of biological processes. In addition to the possibility of studying the source of carbohydrates and their rotation in the environment, analysis of specific stable compounds may be used to trace microbial biomass and to detect food adulteration or in studies

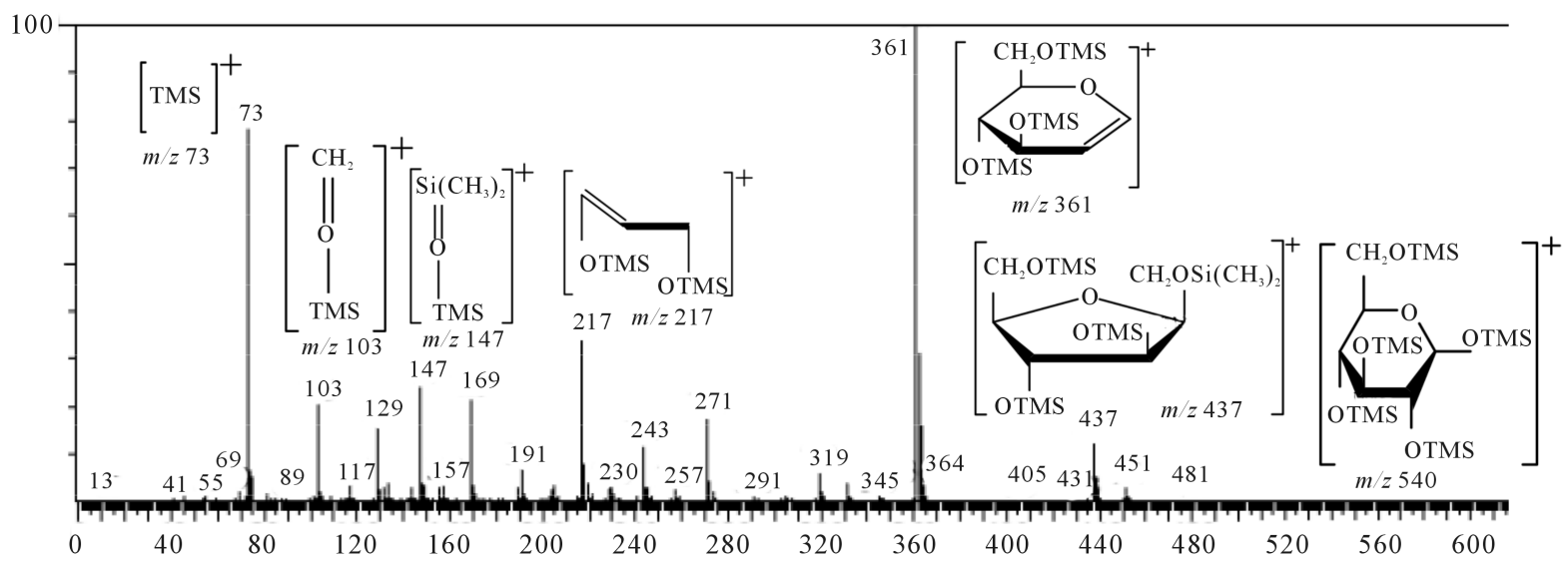

Figure 4. Mass spectrum of TMS-Sucrose. 
nutrition. The techniques used in the analysis have proved very useful, therefore, allowed the identification of various chemical constituents, mainly carbohydrates, from both crude extracts. To our knowledge, this is the first study from hexane and ethanol extracts of the seeds of $X$. ameriacana using silylated derivatives by gas chromatography-mass spectrometry. This study, the first with oil from the seeds of $X$. americana, enabled a possible use of this oil as human or animal nutraceutical ingredient.

\section{Acknowledgements}

The authors thank the Brazilian funding agencies FUNCAP, CAPES and CNPq for financial support.

\section{References}

[1] Sherpad, G.S. (2002) In: Lewinsohn, T.M. and Prado, P.I., Eds., Biodiversidade Brasileira: Síntese do Estado Atual de Conhecimentos, Contexto, St. Paulo, Brasil.

[2] Alameida-Cortez, J.S., Cortez, P.H.M., Franco, J.M.V. and Uzunian, A. (2013) Caatinga. 2nd Edition, Coleção Biomas do Brasil, Ed. Harbra, St. Paulo.

[3] Brasileiro, M.T., Egito, A.A., Lima, J.G., Randau, K.P., Perreira, G.C. and Neto P.J.R. (2008) Ximenia americana L.: Botânica, Química e Farmacologia no Interesse da Tecnologia Farmacêutica. Revista Brasileira de Farmácia, 89, 164167. http://www.rbfarma.org.br/files/pag_164a167_ximenia_americana.pdf

[4] Braga, R. (1976) Plantas do Nordeste, Especialmente do Ceará. 3nd Edition, Escola Superior de Agricultura, Mossoró.

[5] Correia, M.P. (1984) Dicionário de Plantas Úteis do Brasil e das Exóticas Cultivadas. Imprensa Nacional, Rio de Janeiro.

[6] Monte, F.J.Q., Lemos, T.L.G., Araújo, M.R.S. and Gomes, E.S. (2012) Chapter 20. In: Rao, V., Ed., Phytochemicals, a Global Perspective of Their Role in Nutrition and Health, INTECH, Rijeka, Croatia, 429.

[7] Isidorov, V.A. and Szczepaniak, L. (2009) Gas Chromatographic Retention Indices of Biologically and Environmentally Important Organic Compounds on Capillary Columns with Low-Polar Stationary Phases. Journal of Chromatography A, 1216, 8998-9007. http://dx.doi.org/10.1016/j.chroma.2009.10.079

[8] Clayden, J., Greeves, N., Warren, S. and Wathers, P. (2004) Organic Chemistry. Oxford University Press, Florence.

[9] Budzikiewicz, H., Djerassi, C. and Williams, D.H. (1967) Mass Spectrometry of Organic Compounds. Holden-Day, London.

[10] Silvério, F.O., Barbosa, L.C.A., Silvestre, A.J.D., Piló-Veloso, D. and Gomide, J.L. (2007) Comparative Study on the Chemical Composition of Lipophilic Fractions from three Wood Tissues of Eucalyptus Species by Gas Chromatography-Mass Spectrometry Analysis. Journal of Wood Science, 53, 533-540. http://dx.doi.org/10.1007/s10086-007-0901-0

[11] Diekman, J. and Djerassi, C. (1967) Mass Spectrometry in Structural and Stereochemical Problems. CXXV. Mass Spectrometry of Some Steroid Trimethylsilyl Ethers. Journal of Organic Chemistry, 32, 1005-1012. http://dx.doi.org/10.1021/jo01279a033

[12] Brooks, C.J.W. (1979) Some Aspects of Mass Spectrometry in Research on Steroids. Philosophical Transactions A, 293, 53-67. http://dx.doi.org/10.1098/rsta.1979.0079

[13] Gustafsson, J.A., Ryhage, R., Sjöval, J. and Moriarty, R.M. (1969) Migrations of the Trimethylsilyl Group upon Electron Impact in Steroids. Journal of the American Chemical Society, 91, 1234-1236. http://dx.doi.org/10.1021/ja01033a045

[14] Chizhov, O.S., Molodtsov, N.V. and Kochetkov, N.K. (1967) Mass Spectrometry of Trimethylsilyl Ethers of Carbohydrates. Carbohydrate Research, 4, 273-276. http://dx.doi.org/10.1016/S0008-6215(00)85016-8

[15] Medeiros, P.M. and Simoneit, B.R.T., (2007) Analysis of Sugars in Environmental Samples by Gas ChromatographyMass Spectrometry. Journal of Chromatography A, 1141, 271-278.

http://dx.doi.org/10.1016/j.chroma.2006.12.017

[16] Ferreira, C. (2011) Caracterização por GC-MS de Glícidos Derivatização Assistida por Microondas. Dissertation, Universidade de Coimbra, Coimbra.

[17] Petersson, G. (1972) A McLafferty Type Rearrangement of a Trimethylsilyl Group in Silylated Hydroxy Carbonyl Compounds. Organic Mass Spectrometry, 6, 577-592. http://dx.doi.org/10.1002/oms.1210060514

[18] Mogoşanu, G.D., Grumezescu, A.M., Mihaiescu, D.E., Istrati, D., Mogoşanu, D.E. and Buteica, S.A. (2011) Identification of Sugars from Silene albae herba Using GC-MS Technique. UPB Scientific Bulletin, Series B, 73, 101-108. http://scientificbulletin.upb.ro/rev_docs_arhiva/full93413.pdf 
[19] DeJongh, D.C., Radford, T., Hribar, J.D., Hanessian, S., Bieber, M., Dawson, G. and Sweeley, C.C. (1969) Analysis of Trimethylsilyl Derivatives of Carbohydrates by Gas Chromatography and Mass Spectrometry. Journal of the American Chemical Society, 91, 1728-1740. http://dx.doi.org/10.1021/ja01035a022

[20] Karady, S. and Pines, S.H. (1970) Mass Spectrometry of the Trimethylsilyl Ethers of 2-ketohexoses. Tetrahedron, 26, 4527-4536. http://dx.doi.org/10.1016/S0040-4020(01)93099-6

[21] García-Raso, A., Fernández-Diaz, M., Páez, M.I., Sanz, J. and Castro, I.M. (1989) Gas Chromatographic Retention of Carbohydrate Trimethylsilyl Ethers. Ketohexoses. Journal of Chromatography, 471, 205-216. http://dx.doi.org/10.1016/S0021-9673(00)94168-2

[22] Curtius, H.-Ch., Müller, M. and Völlmin, J.A. (1968) Studies on the Ring Structures of Ketoses by Means of Gas Chromatography and Mass Spectroscopy. Journal of Chromatography, 37, 216-224. http://dx.doi.org/10.1016/S0021-9673(01)99098-3

[23] Henrique, M.C., Nunomura, R.C.S., Nunomura, S.M. and Silva, S.G. (2014) Constituintes Químicos Isolados dos Galhos e Cascas de Ampazeiro (Parahancornia amapa, Apocynaceae). Acta Amazonica, 44, 533-538. http://dx.doi.org/10.1590/1809-4392201305233

[24] Mahato, S.B. and Kundu, A.P. (1994) ${ }^{13}$ C NMR Spectra of Pentacyclic Triterpenoids-A Compilation and Some Salient Features. Phytochemistry, 37, 1517-1575. http://dx.doi.org/10.1016/S0031-9422(00)89569-2

[25] Costa, D.A., Chaves, M.H., Silva, W.C.S. and Costa, C.L.S. (2010) Constituintes Químicos, Fenóis Totais e Atividade Antioxidante de Sterculia striata St. Hil. et Naudin. Acta Amazonica, 40, 207-212. http://dx.doi.org/10.1590/S0044-59672010000100026 